\title{
NORMAL SCHOOLS OF THE NEW STATE
}

\author{
N. S. COWART
}

Superintendent of City Schools, Wilburton, I. T.

That there is a crying need for normal schools in our new state of Oklahoma may be seen on every hand. In many places it has been impossible to get normal-trained teachers for the schools in Indian Territory; some places have been filled by girls who had only finished the sixth grade, for the reason that better teachers could not be secured. In all the states there is a scarcity of well-prepared teachers, and even in Massachusetts, the cradle of the normal school in the United States, only 48 per cent. of the teachers are normal graduates.

If we are to have an ideal commonwealth; if we are to have the best possible schools; if we expect to build a citizenship that will maintain and further develop our public institutions, we must not be satisfied with teachers that are in any way inferior to those of any state, or any country of the world.

Experience is a great factor in successful work in the schoolroom, and teachers having special preparation stay longer in the work, and therefore accomplish more. Those not well fitted become discouraged, disgusted with their own efforts, and quit the work often just at the time when they should be coming into their useful period. These persons are largely responsible for low salaries and the failure of teachers' unions.

The first normal school in the United States was started in Massachuetts in 1839 . The idea grew rapidly and spread from state to state. At present Massachusetts' number has reached ten, while New York and Pennsylvania each has fifteen normal schools. These three states have nearly one-fourth of all the normal schools, and more than one-third of the normal students, in the United States. While these states are leading in this important work, many others are following them closely; and, 
notwithstanding the fact that the colleges and universities have tried to show cause why the normal school should not exist, the idea is constantly growing, and we might with safety say that a state's educational standing may be measured by its institution's for the training of teachers.

Oklahoma now has three such institutions, and from reports they are all doing good work. We need more.

We should have one strong central normal school equipped to do all that any school of the kind can do, and several rightly located ones that would be at least sufficiently complete to prepare teachers for the common schools. In all, we should have, in my opinion, not fewer than four, and not more than six, of these schools. Later, as our population and schools increase more can be established, if necessary.

It would be better if the teachers in these schools could first have a college or university course, and then a normal course. This would prevent the oft-occuring trouble of having teachers in the faculty who are not thoroughly in sympathy with normal school work. The academic work of the normal school should be as well taught as that of the university, and then so recognized by the state; for a normal-school student must have not cnly a reciting knowledge of a subject, but also a teaching knowledge; and this should mean a thoroughness not attempted by many of our university students.

A normal school should have a model, a practice, and a experimental department. The first two are nearly always in evidence, but the experimental department is doubtless too much neglected. Dr. Roark says that each professor of teaching, and his body of carefully selected, fit students, should try to push the frontier of pedagogy a little farther out, and that there can be no good reason given why they should not have the franking privilege, that they may send out the results of their experiments even to the most remote country districts, just as many states send out reports of agricultural experiments.

There is a school in Indiana and one in Oregon that maintain practice departments for rural schools; and why such an important thing should be overlooked by most of our normal 
schools I am unable to see. In West Virginia and Arizona the students visit the rural schools accompanied by the teacher of pedagogy. So far as I am able to learn, there are only six schools in the United States that maintain practice departments for the high-school work. In our new state it would probably be better to have this work only in our central school.

Theory and practice should go hand in hand, and the teacher of methods should be the one to apply them in the model department. Only about one-tenth of our schools have this arrangement.

If the normal school has a right to exist, it deserves more recognition than is given it. If it be required of the state to furnish such schools, it should be required of the teachers that they attend these schools. I believe our new state should take a step in advance of what has been done elsewhere, and require all teachers not now in the service, after a certain fixed period of time, to present a normal diploma as a certificate to teach.

Our central school should have a course for county and city superintendents and institute workers, and the people should demand this preparation. And I can see no reason why we should not also have normal extension work and a library course. In my judgment, the state will be amply able to support these schools.

The Indian Territory will want at least two of the schools, and the teachers will do their best to see that they are located where they will serve the greatest number of people, and not placed by the overanxious town-boomers.

We would recommend that a committee be appointed by this association to take such steps as may be necessary to protect all the educational interests of the new state. 